\title{
The Effect of Voluntary Participation on Cooperation
}

23 June 2017

\author{
Daniele Nosenzo ${ }^{1}$ and Fabio Tufano**
}

\begin{abstract}
:
We study the effects of voluntary participation on cooperation in collective action problems. Voluntary participation may foster cooperation through a mechanism of assortative selection of interaction partners based on false consensus bias, or through a mechanism whereby the decision to not participate can be used as a threat against free-riders. We examine the effectiveness of these mechanisms in a one-shot public goods experiment. Voluntary participation has a positive effect on provision only through the threat of non-participation. Assortative selection of interaction partners seems to play a minor role in our setting, whereas the threat of nonparticipation is a powerful force to discipline free-riding.
\end{abstract}

Keywords: collective action; cooperation; voluntary participation; experiment.

JEL Classification Numbers: C91, D02, H41

Acknowledgements: We thank the Editor, Dirk Engelmann, and one anonymous referee for very useful comments. We also received helpful suggestions from Despoina Alempaki, Abigail Barr, Tim Cason, Dennie van Dolder, Simon Gächter, Benedikt Herrmann, Felix Kölle, Anita Kopanyi-Peuker, Xueheng Li, Maria Montero, Rebecca Morton, Tatsuyoshi Saijo, Heiner Schumacher, Martin Sefton, Chris Starmer, Aljaz Ule, Jörg Weber as well as workshop participants at the University of Aarhus and University of Amsterdam, and participants at the 2014 North-American ESA conference. We acknowledge support from the Leverhulme Trust (ECF/2010/0636), Center for Interdisciplinary Studies in Economics Psychology and Social Sciences (CISPES, Università degli Studi di Milano-Bicocca), and the University of Nottingham.

\footnotetext{
${ }^{1}$ Corresponding author. School of Economics, University of Nottingham, University Park, NG7 2RD, UK. E-mail address: daniele.nosenzo@nottingham.ac.uk.

** School of Economics, University of Nottingham, UK. E-mail address: fabio.tufano@ nottingham.ac.uk.
} 


\section{INTRODUCTION}

Collective action is at the heart of many activities of vital importance for human societies. However, many groups fall prey to free-riding incentives and struggle to foster and sustain cooperation (Olson, 1965; Dietz et al., 2003). Thus, the success of human cooperation relies on the effectiveness of mechanisms and institutions designed to restrain free-riding and promote cooperation (e.g., Rand and Nowak, 2013). A substantial amount of research has been devoted to the study of such mechanisms and institutions. Several authors have shown that cooperation can be sustained by (in)direct reciprocity and reputational spill-overs, if the prospects of future interactions are non-negligible (e.g., Roth and Murnighan, 1978; Dal Bó, 2005). Altruistic punishment and rewards have also been shown to effectively promote cooperation (e.g., Fehr and Gächter, 2000; Sefton et al., 2007). In this paper, we study an alternative mechanism to reciprocity, reputation, punishment and rewards: voluntary participation to collective action.

Voluntary participation is a nearly ubiquitous characteristic of real-world social interactions: in many naturally occurring environments individuals can freely decide whether or not to partner with others to engage in cooperative endeavors. Voluntary associations, collectives, community groups, and collaborative institutions are typical real-world examples of organizations facing collective action problems where agents have the freedom to join in, or opt out from, participating in the common endeavors. And indeed voluntary participation is sometimes invoked to explain the relative success of such groups in solving collective actions dilemmas (e.g., Lin, 1990, and the symposium articles featured in the Journal of Comparative Economics - vol. 17, issue 2 - for a discussion of the role of voluntary participation in Chinese agricultural collectives in 1959-1961). However, while there is a consensus that voluntary participation may foster cooperation, little is known about the mechanisms underlying this effect. The aim of this study is to contribute filling this gap in the literature by investigating the potential mechanisms that may make voluntary participation conducive to cooperation.

We focus on two specific mechanisms that have received substantial attention especially in the theoretical literature on voluntary participation. On the one hand, some authors have argued that the positive effects of voluntary participation may operate through a mechanism of assortative matching: the fact that participation in groups is not forced but voluntary may trigger a process of self-selection into groups that favors the inclusion of cooperators and the exclusion 
of free-riders. The literature has proposed different ways in which this process of assortative matching may arise. For instance, some authors have suggested that cooperators may have observable characteristics ("green beards") that distinguish them from free-riders (e.g., Frank, 1987; 1988; Amann and Yang, 1998). If individuals are free to decide whether or not to enter into partnerships with others, they may use these observable characteristics to avoid partnerships with free-riders and favor partnerships with cooperators. Other models have instead proposed that assortative matching may be the result of a "false consensus bias", whereby individuals tend to project their own cooperative attitudes onto others (Ross et al., 1977). ${ }^{1}$ If individuals suffer from a false consensus bias, cooperators will be more optimistic about the prospects of cooperation, and may thus be more likely than free-riders to join others in cooperative endeavors (e.g., Orbell and Dawes, 1991; Macy and Skvoretz, 1998).

On the other hand, another strand of literature emphasizes a different mechanism: when participation is voluntary individuals are free to walk away from either potential or existing partnerships, and this can be used as a sanctioning device to discipline free-riders. Again, the existing literature suggests different possible mechanisms whereby this may happen. In some models, the possibility to quit partnerships is beneficial to cooperation simply because it allows cooperators who are willing to walk away from their partners, to avoid repeated interactions with free-riders and to reap instead the benefits of repeated interactions with other like-minded cooperators (e.g., Aktipis, 2004). Other authors emphasize instead the fact that the dissolution of partnerships may impose costs on all parties involved (e.g., Fujiwara-Greve and Okuno-Fujiwara, 2009; Izquierdo et al., 2010; Schumacher, 2013; Izquierdo et al., 2014). This gives group members a means to resist exploitation by free-riders, as the threat of costly exits may discipline opportunistic behavior and prevent free-riding.

Despite the many theoretical arguments proposing that voluntary participation may foster cooperation, only a few empirical studies (reviewed below) have so far examined the effects of voluntary participation on cooperation. Moreover, none of these studies have compared the relative effectiveness of the mechanisms outlined above in promoting cooperation. In this paper,

\footnotetext{
${ }^{1}$ Several experimental studies have found evidence that individuals suffer from a false consensus bias across a variety of settings (e.g., Offerman et al., 1996; Selten and Ockenfels, 1998; Charness and Grosskopf, 2001; Heijden et al., 2007; Gächter et al., 2012; Blanco et al., 2014). For a discussion of whether the consensus effect is "truly" false, see Engelmann and Strobel (2000) and Engelmann and Strobel (2012).
} 
we present a one-shot, two-person public goods game experiment designed to disentangle the effects on cooperation of voluntary participation operating either through a mechanism of assortative matching based on false consensus bias or through a mechanism whereby the decision not to participate can be used as a threat against free-riding. To disentangle these effects, we contrast three treatments: a Baseline treatment, with forced participation in the public goods game; an Unconditional voluntary participation treatment ('Unconditional treatment,' henceforth) where at the beginning of the game players choose between an outside option payoff and participation in the public goods game; and a Conditional voluntary participation treatment ('Conditional treatment,' henceforth) where, after interacting in the public goods game and precommitting to a contribution, players can opt out of the game and secure an outside option payoff.

The key design difference between the Unconditional and Conditional treatments hinges on the information available to players when deciding whether to participate in the game: in the Conditional treatment players can condition their participation decision on the pre-committed contributions (which will of course be implemented only if players do not opt out of the game); thus, voluntary participation can be used as a sanctioning device since players can (tacitly) threaten to walk away from potential partnerships with free-riders. In contrast, in the Unconditional treatment the participation decision is made unconditionally (i.e., without receiving any information about contribution decisions) and cannot thus be used as a sanctioning device. However, voluntary participation may still be beneficial if cooperative types self-select into the game more often than free-riders. In order to study the role of false consensus bias in triggering this assortative matching effect, in all treatments the public goods game was preceded by a sequential two-player prisoner's dilemma game which we use to measure subjects' cooperative types and optimism about cooperation.

Our results show that voluntary participation can have a strong, positive effect on cooperation. However, this positive effect is only observed in the Conditional treatment, whereas in the Unconditional treatment voluntary participation does not have an effect on cooperation. These findings point to the crucial relevance of the sanctioning mechanism in fostering cooperation in collective action situations. The effectiveness of this mechanism lies in the threatvalue of voluntary participation: in our experiment subjects who decide not to participate do so mainly to retaliate against free-riders. Subjects seem to anticipate this effect, and this generally 
increases contributions. In contrast, the assortative matching mechanism does not have much bite in our experiment. This is not because our subjects are not affected by a false consensus bias: in fact, we observe a significant false consensus effect in our data. Rather, the assortative matching mechanism is unsuccessful because in our experiment decisions to enter the public goods game do not seem to depend on subjects' cooperation types or their optimism about cooperation.

Our paper contributes to the study of mechanisms and institutions that can help groups overcome collective action dilemmas. We show that the institution of voluntary participation can substantially increase cooperation, and may thus be either an effective substitute or complement for other mechanisms based - for instance - on reciprocity, reputation, direct punishment, and rewards. As such, our paper directly contributes to the small experimental literature on the effects of voluntary participation in social dilemmas. ${ }^{2}$ Ehrhart and Keser (1999) were among the first to study the effects of voluntary participation on public good provision. In their experiment, subjects are initially assigned to public good groups, but have then the opportunity to migrate to other groups, or create new ones. They observe a positive effect of voluntary participation on cooperation, in that contributions levels are above the theoretical prediction and closer to the socially efficient level. Hauk (2003) studies voluntary participation in repeated n-person prisoner's dilemma games where players can choose between playing the game and securing an outside option payoff, and finds a positive effect on cooperation. My and Chalvignac (2010) compare a standard repeated public goods game with a game with two stages: in the first stage subjects decide whether or not to participate in the game; in the second stage subjects who decided to participate choose a contribution level, whereas subjects who opted out receive an outside option payoff. They find a weak but positive effect of the opt-out option on contributions. ${ }^{3}$

\footnotetext{
${ }^{2}$ Another, less closely related, literature entails the study of endogenous group formation in social dilemmas (e.g., Riedl and Ule, 2002; Cinyabuguma et al., 2005; Page et al., 2005; Ahn et al., 2008; 2009; Maier-Rigaud et al., 2010; Charness and Yang, 2014). The main focus of this literature, however, is on the effects of mechanisms, such as voting, partner-selection and ostracism that allow group members to regulate the participation of other individuals in their group. In contrast, the focus of our paper is on the decisions of the individual to self-select into or out of cooperative endeavors.

${ }^{3}$ Voluntary participation has also been studied in the context of team production games (e.g., Keser and Montmarquette, 2011). Also related are the experiments by Cason et al. (2002) and Cason et al. (2004), who study a two-stage, non-linear public goods game where, in the first stage, subjects can commit to free-ride by announcing their non-participation in the game, and in the second stage subjects who have not committed to free-ride choose a contribution level.
} 
A key difference between the studies mentioned above and our experiment is that previous studies typically entail repeated interactions between subjects, where the decisions to participate in a future round of interaction are made after having observed the outcome of previous interactions. This makes it difficult, if not impossible, to identify the distinctive roles of mechanisms based on assortative matching or sanction threats in promoting cooperation, as the two types of mechanisms are confounded in those experimental designs. In contrast, our experiment is inspired by the theoretical arguments discussed above that emphasize the different effects that these mechanisms may have on cooperation. Thus, our experiment is based on oneshot games where we can cleanly identify which mechanism drives the effects of voluntary participation on cooperation.

In this sense, our paper is most closely related to the experiments by Orbell and Dawes (1993), who study non-repeated prisoner's dilemma games with an unconditional participation option (subjects can decide whether to cooperate, defect, or not play the game), and Wilson and Wu (2017), who study infinitely repeated prisoner's dilemma games where players have an exit option to unilaterally and irrevocably terminate the relationship and secure an outside option payoff. However, Orbell and Dawes (1993) only focus on an assortative matching effect and Wilson and $\mathrm{Wu}$ (2017) only focus on sanctioning effects, whereas our experiment provides a unified framework where we can compare the relative effectiveness of either mechanism on cooperation. In line with our results, Wilson and $\mathrm{Wu}(2017)$ find that the presence of an exit option can substantially increase cooperation. Orbell and Dawes (1993) find that unconditional participation can also have a positive effect on cooperation and efficiency, which is in contrast to our finding. While the numerous differences between experimental designs make it difficult to precisely identify the source of this variation in experimental results, these discrepancies suggest that the specific details of the decision-making environment may play an important role in determining the effectiveness of participation. This may be an interesting issue for further research.

The paper progresses as follows. Section 2 introduces the experimental design and procedures. Section 3 presents the results and discusses the main findings. Section 4 concludes. 


\section{EXPERIMENT Design ANd Procedures}

\subsection{Experiment design}

Our experiment is based on a one-shot version of the following two-person public goods game (PGG). At the beginning of the game, subjects are randomly matched into two-person groups. In each group, subjects receive an endowment of 20 tokens each, and simultaneously decide whether to allocate these tokens to either a private or a group account. Each token a subject allocates to the private account earns 3 points to that subject, whereas each token allocated to the group account earns 2 points to each of the two subjects in the group (in the experiment point earnings were converted to cash at a rate of 0.15 GBP per point). Thus, the game contains a tension between private and collective interests: group payoffs are maximized when subjects allocate their whole endowment to the group account, resulting in a payoff of 80 points per subject. However, the optimal decision of a self-interested individual is to allocate all tokens to the private account, resulting in an equilibrium payoff of 60 points per subject.

We study different versions of this game across three between-subject treatments, where we vary whether and how subjects can voluntarily participate in the PGG. In a Baseline treatment there is no option of voluntary participation and subjects are required to participate in the PGG. In contrast, in our Unconditional and Conditional treatments subjects choose whether or not to play the PGG. The two treatments differ in whether subjects can express their voluntary participation before or after having obtained information about their opponent's contribution.

The Unconditional treatment is based on a two-stage game where, in the first stage, subjects simultaneously decide whether to participate in the PGG or take an outside option payoff of 61 points, that is just above the Nash equilibrium payoff of the underlying PGG (see Section 2.2 for further discussion of the theoretical implications of this design choice). In the second stage, subjects learn their opponent's participation decision. If both subjects have chosen to participate in the game, subjects play the one-shot PGG and are paid accordingly. If at least one subject in the group has chosen not to participate in the PGG, then both subjects receive the outside option payoff. ${ }^{4}$

\footnotetext{
${ }^{4}$ Note that in this sense the public good is not truly non-excludable in our setting, because a player's choice not to take part in the game prevents both players from enjoying the benefits of public good provision. We made this choice for simplicity, to avoid the complications of having to specify the structure of payoffs in case only one player commits to provide the public good.
} 
The Conditional treatment is also based on a two-stage game, but the option of voluntary participation is available in the second stage. In the first stage, subjects make a simultaneous contribution decision in the PGG. In the second stage, subjects learn their opponent's contribution and simultaneously decide whether to confirm or withdraw their participation. If both subjects confirm their participation, subjects are paid according to the contribution decisions of stage one. If at least one subject withdraws participation, then both subjects receive the outside option payoff of 61 points.

We use the Conditional treatment to study the effect of the threat-value of voluntary participation on cooperation. As we discussed in the previous section, the theoretical literature suggests that the freedom to reject a partnership has a positive effect of cooperation because it gives cooperators a means to discipline free-riders: given that a rejection imposes costs on both those who reject the partnership and their potential partners, cooperators can use it as threat to restrain opportunistic behavior and encourage cooperation. In our experiment we capture the essence of this mechanism by specifying a relatively low outside option payoff, which make nonparticipation potentially costly. That is, if subjects decide to reject a partnership, this may lead to lower payoffs to both interacting parties, and thus players can use this as a threat to deter freeriding.

The Unconditional treatment allows us instead to study the effect of false consensus bias on cooperation. As discussed above, false consensus bias makes cooperators relatively more optimistic than free-riders about the prospects of interacting with a cooperator. If players are free to decide whether to participate in cooperative endeavors, false consensus bias may lead to a process of assortative matching whereby cooperators are more likely to self-select into the PGG than free-riders, with positive effects on cooperation.

To study the false consensus mechanism in more detail, one needs to (i) classify whether subjects are "cooperators" or "free-riders", and (ii) measure their relative optimism about the prevalence of cooperators in their session. To do this, in all treatments the PGG was preceded by a one-shot version of the sequential prisoner's dilemma game (PD). At the beginning of the game, the first-mover chooses whether to cooperate or defect. If the first-mover defects the game ends and players receive a payoff of 50 points each. If the first-mover cooperates then the second-mover chooses between cooperation (where players receive 70 points each) and defection 
(where first- and second-movers receive respectively 35 and 85 points). ${ }^{5}$ In the experiment, subjects were randomly matched in pairs and made decisions in both roles. Subjects did not learn which role they were actually assigned to until the end of the experiment. Thus, both choices were elicited in an incentive-compatible way. Moreover, subjects were asked to submit a prediction about the number of other participants in the session who would cooperate in the role of second-mover. This prediction was incentivized and subjects received 10 points if their guess was correct. ${ }^{6}$

The PD game allows us to perform a more detailed test of the effect of false consensus bias on cooperation. First, based on their choices as second-mover, we can classify each subject as either a "cooperator" (if they cooperated) or "free-rider" (if they defected). Moreover, by eliciting subjects' beliefs about others' behavior in the role of second-mover, we can measure their estimate of the likelihood of meeting a cooperator, i.e. their "optimism" about cooperation.

\subsection{Theoretical considerations}

In the version of the PGG played in the Baseline treatment it is a dominant strategy for a rational and self-interested player to allocate all tokens to their private account. Thus, both players contribute zero tokens to the public good in the unique Nash equilibrium of the game, resulting in an equilibrium payoff of 60 points per subject.

Assuming common knowledge of rationality and self-interest, the option of voluntary participation does not lead to higher predicted contributions in the Unconditional treatment. To see this, consider the second stage of the Unconditional game. In the subgame where subjects make a contribution decision in the PGG, the optimal decision of a rational and self-interested player is to contribute zero tokens, yielding an equilibrium payoff of 60 points per player. By replacing this subgame with its subgame perfect equilibrium value, we obtain the following reduced game (Table 1).

\footnotetext{
${ }^{5}$ Note that the structure of the game is similar to the binary trust game used by Charness and Dufwenberg (2006).

${ }^{6}$ Since subjects were paid both for their choices in the PD game and their beliefs, a concern is that subjects may report distorted beliefs to hedge against their play in the game. Blanco et al. (2010), however, find no evidence of hedging in a sequential prisoner's dilemma game.
} 
Table 1: Reduced Unconditional game

\begin{tabular}{lcc}
\hline \hline & \multicolumn{2}{c}{ PLAYER 2 } \\
\cline { 2 - 3 } PLAYER 1 & Participate & Do not participate \\
\hline Participate & 60,60 & 61,61 \\
Do not participate & 61,61 & 61,61 \\
\hline
\end{tabular}

The reduced game has multiple pure-strategy equilibria and in any equilibrium at least one subject refuses to take part in the PGG. Indeed, in the reduced game players have a weakly dominant strategy not to participate in the PGG and take the outside option payoff of 61 points, instead. Thus, if we refine the equilibrium set by requiring that players do not use weakly dominated strategies, only the equilibrium with mutual non-participation survives. Thus, the public good is not provided in equilibrium and each subject earns a payoff of 61 points.

In contrast, in the Conditional treatment voluntary participation can lead to small, positive contributions in equilibrium. To see this, consider the subgames following the contribution stage. In any subgame, mutual non-participation is always an equilibrium, leading to a payoff of 61 for each player. However, other pure-strategy equilibria may also arise, some of which involve mutual participation, depending on the contributions made in the contribution stage. Specifically, there are three cases. First, in some subgames mutual participation would lead to payoffs that are strictly higher than 61 for both players. In these subgames, participating in the PGG is a weakly dominant strategy (within the subgame) for both players. Using weak dominance as a refinement, we select the equilibrium with mutual participation in these subgames. Second, in other subgames, mutual participation would lead to payoffs that are either equal to 61 for both players, or strictly lower than 61 for at least one player. In these subgames, any equilibrium involves a payoff of 61 for each player. Finally, in a third class of subgames, mutual participation would lead to a payoff of 61 for one player, and a payoff higher than 61 for the other player. In these subgames, participating in the PGG is a weakly dominant strategy (within the subgame) for the player who receives a payoff higher than 61 from participation, while the other player is indifferent between participation and non-participation. Thus there are three pure-strategy equilibria, one involving mutual participation and two involving non-participation by at least one player. In these subgames we select the equilibrium involving mutual participation on the 
grounds that this equilibrium is strictly preferred by one player while the other player is indifferent between equilibria. ${ }^{7}$

By replacing each subgame with its subgame perfect equilibrium value, we obtain a reduced game with five pure-strategy equilibria. Three equilibria involve symmetric contributions to the public good of respectively zero, one and two tokens. In the remaining two equilibria one player contributes zero tokens and the other player contributes one token. Note that in the two asymmetric equilibria and in the symmetric equilibrium with zero contributions at least one player earns a PGG payoff lower than 61. Thus, in the corresponding subgame perfect equilibria of the extended game players withdraw participation from the PGG and the public good is not provided. In the remaining two symmetric equilibria, both players earn at least 61 points from the PGG and thus they confirm their participation in the PGG in the corresponding subgame perfect equilibria of the extended game. ${ }^{8}$

No other pure-strategy equilibria exists. To see this, note first that there cannot be equilibria with contribution profiles where players contribute more than 2 tokens. Following such contribution profiles two possible situations arise. First, if players' contributions are too different from each other, then participation leads to a payoff of 60 or lower for one player, thus triggering non-participation in the corresponding subgame and a payoff of 61 to both players. But then, at the contribution stage, players can deviate to contribution levels that lead to participation and thus increase payoffs. Second, if players' contributions are not too different from each other, then participation leads to a payoff of at least 61 for both players and players confirm their participation in the PGG. But then the usual incentives to free-ride exist and at the contribution stage (at least) the player who contributes more has an incentive to deviate to a lower contribution (as long as it does not trigger non-participation). Finally, note that there cannot be equilibria where one player contributes 2 tokens and the other contributes 1 or 0 tokens: in this case players withdraw participation in the corresponding subgame, leading to a payoff of 61 . But then, at the contribution stage, the player that contributes 1 or 0 tokens has an incentive to increase her contribution to 2 tokens, thus ensuring a payoff of 62 .

\footnotetext{
7 This has only minor implications for the set of subgame-perfect equilibria, as we discuss in the next footnote.

${ }^{8}$ If in the subgames where mutual participation leads to a payoff of 61 for one player and a payoff higher than 61 for the other player we select the equilibrium with non-participation, the set of subgame-perfect equilibria changes slightly as there is now a sixth equilibrium involving symmetric contributions of three tokens to the public good.
} 
Overall this analysis shows that, according to standard predictions, voluntary participation has only a small positive effect on public good provision. Moreover, this positive effect obtains only when voluntary participation can be conditioned on the opponent's contribution decision.

These predictions may change if we relax the assumption that all individuals are selfinterested and assume that at least some individuals have other-regarding preferences. In this case, positive contributions may emerge in equilibrium already in the Baseline treatment. To illustrate this point, assume that players have Fehr-Schmidt (1999) preferences so that player $i$ 's utility is given by:

$$
U_{i}=\pi_{i}-\alpha_{i}\left[\max \left\{\pi_{j}-\pi_{i}, 0\right\}\right]-\beta_{i}\left[\max \left\{\pi_{i}-\pi_{j}, 0\right\}\right]
$$

for $i \neq j$, and where $\pi_{i}$ is the player's material payoff from the game, the parameter $\alpha_{i}$ measures her aversion to disadvantageous payoff inequality, and the parameter $\beta_{i}$ measures her aversion to advantageous payoff inequality. Fehr and Schmidt assume that $\beta_{i} \leq \alpha_{i}$ and $0 \leq \beta_{i}<1$. As we show in the online appendix, if players have a sufficiently strong distaste for advantageous inequality $\left(\beta_{i}>1 / 3\right)$, then any symmetric contribution profile is an equilibrium already in the Baseline treatment.

In the presence of other-regarding players, positive contributions and provision of the public good can also occur when there is an unconditional participation option. To see this, consider first the case where players know each other's preferences. In the online appendix we show that if two sufficiently inequity averse players $\left(\beta_{i}>1 / 3\right)$ are matched together in the Unconditional treatment, then the only equilibrium in undominated strategies involves participation and symmetric positive contributions. However, if either player is not sufficiently inequity averse $\left(\beta_{i}<1 / 3\right)$, then the equilibrium involves non-participation and the public good is not provided. Thus, when players know each other's preferences, the prediction is that (sufficiently) other-regarding players participate and provide the public good, while players who are not other-regarding do not participate.

A similar mechanism of assortative matching may also take place if players do not know each other's preferences, but suffer from a false consensus bias. If players do not know the preferences of their opponent, they will base their decision of whether to participate in the PGG on their expectations about the proportions of other-regarding and self-interested players in the population. If players suffer from a false consensus bias, then other-regarding players are more 
optimistic than self-interested players about the chances of meeting another other-regarding player. Therefore, they may be more likely to sort themselves into the PGG than self-interested players, triggering a process of assortative matching that also leads to public good provision. ${ }^{9}$

Finally, the presence of other-regarding players may also strengthen the positive effects of conditional participation on contributions. In the online appendix we show that if players have a sufficiently strong distaste for disadvantageous inequity $\left(\alpha_{i}>5.67\right)$, then any symmetric positive contribution profile can be sustained in equilibrium, including the profile with full contributions. ${ }^{10}$ This is because players with other-regarding preferences may be willing to withdraw participation from the PGG even if this implies a sacrifice in their own material payoffs. Thus, threats that are not credible for self-interested players may become credible if players have other-regarding preferences, and this may further discipline free-riders. ${ }^{11}$

\subsection{Experiment procedures}

The experiment was programmed in z-Tree (Fischbacher, 2007) and conducted at the University of Nottingham using students from a wide range of disciplines recruited through the online recruitment system ORSEE (Greiner, 2015). We conducted fourteen sessions: four sessions with a total of 68 subjects in each of Baseline and Conditional, and six sessions with a total of 92 subjects in Unconditional. We over recruited in the Unconditional treatment to account for potential attrition of subjects out of the PGG and we kept recruiting subjects until we obtained contribution decisions from 68 subjects in this treatment as well.

At the start of a session, subjects were randomly allocated to computer terminals and were given preliminary experimental instructions, which were read aloud (instructions are available in the online appendix). Subjects were informed that the experiment consisted of two parts, but they did not receive instructions for part two (the PGG) until everyone had completed part one (the PD game). Subjects were then given part-one instructions, which were again read aloud. These

\footnotetext{
${ }^{9}$ See Orbell and Dawes (1991) for a model of selective cooperation when players suffer from false consensus bias. ${ }^{10}$ This level of disadvantageous inequity aversion is high. Blanco et al. (2011), for instance, find that only $13 \%$ of subjects in their experiment have $\alpha_{i} \geq 4.5$. However, even for smaller levels of $\alpha_{i}$, one can sustain positive contribution profiles in equilibrium where both players contribute more than 2 tokens (the highest contribution profile that can be sustained with self-interested players). See the online appendix for details.

${ }^{11}$ This is akin to rejection of low offers in ultimatum games (which the Conditional treatment indeed resembles). There, the average rejection rate is about 16 percent (Oosterbeek et al., 2004), with low offers being rejected more readily (about half of the time, see Camerer, 2003) than higher offers.
} 
instructions were followed by a series of control questions aimed at testing subjects' understanding of the PD game. Part one began once all subjects had answered all questions correctly. Subjects were then randomly matched in pairs and played the one-shot PD game described above.

When everyone had completed part one, and without receiving feedback on the outcomes of the PD game, subjects were given part-two instructions, which were read aloud. Again, the instructions were followed by control questions to probe subjects' understanding of the game. Part two began when everyone had answered all questions correctly. Subjects were then randomly matched into new pairs and played one of the three versions of the PGG described above.

At the end of part two, subjects were informed of their earnings from the two parts of the experiment. For part one, in each pair one of the subjects was randomly assigned the role of firstmover and the other subject the role of second-mover. One of the two parts was then randomly selected for payment, and subjects were paid accordingly in private and in cash while they were completing a short post-experimental questionnaire, where we elicited standard sociodemographic and attitudinal information. The questionnaire included a self-assessment of subjects' risk and trust attitudes. Risk attitudes were elicited using the German Socio-Economic Panel (SOEP) general risk question discussed in Dohmen et al. (2011), and trust attitudes were elicited using the World Values Survey (WVS) Trust question. ${ }^{12}$ Sessions lasted approximately 60 minutes and earnings averaged GBP 9.13.

\section{RESULTS}

\subsection{Contribution behavior across treatments}

Figure 1 summarizes the main result of the experiment. The left panel of the figure shows the average contributions to the public good as percentage of endowment in our three treatments. In

\footnotetext{
12 The SOEP question reads: "Are you generally a person who is fully prepared to take risks or do you try to avoid taking risks?", and subjects answered on a Likert scale ranging from 0 ("risk averse") to 10 ("fully prepared to take risk"). The average response to the SOEP risk question was 5.64 (s.d. 2.12). The WVS Trust question reads: "Generally speaking, would you say that most people can be trusted or that you need to be very careful in dealing with people?", to which subjects replied either by saying that they believe that "most people can be trusted" or that one needs "to be very careful in dealing with people". Responses to the WVS Trust question reveal that about $41 \%$ of our subjects believe that "most people can be trusted".
} 
the right panel of the figure we plot, for each treatment, the cumulative distribution function (CDF) of contributions as percentage of the subjects' initial endowment.

Figure 1: Contributions to public good across treatments
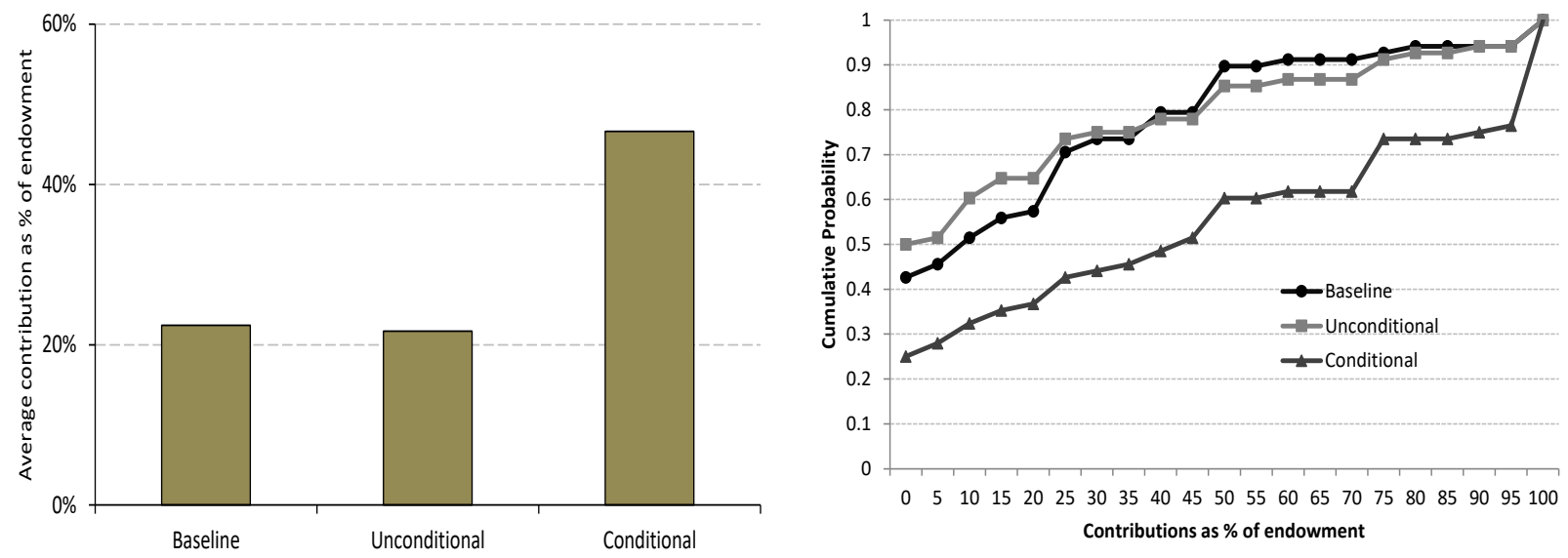

On average in Baseline subjects contribute about $22 \%$ of their endowment to the public good. The right panel of Figure 1 shows that a substantial fraction of subjects (43\%) act as complete free-riders and make no contributions to the public good. Only $10 \%$ of subjects contribute at least half of their endowment, and only $6 \%$ contribute the entire endowment. The average contribution rate in Baseline is similar to those reported in the one-shot public goods game experiments by Cubitt et al. (2011), Dufwenberg et al. (2011) and Fischbacher et al. (2012), who also find average contributions in the 20\%-30\% range. Other one-shot experiments report average contributions in the 35\%-45\% range (Gächter et al., 2004; Gächter and Herrmann, 2009), while Walker and Halloran (2004) find an average contribution rate of 53\%. Overall, these results show that the prospects for cooperation among strangers can be dismal in the absence of mechanisms that can discipline free-riding. The question is whether voluntary participation can be used as such a mechanism to improve cooperation.

Figure 1 suggests that the answer is positive, although the effectiveness of voluntary participation crucially depends on whether the participation decision can be conditioned on the opponent's contributions. In particular, the Conditional treatment produces a more than two-fold increase in contributions relative to Baseline: subjects contribute on average $47 \%$ of their endowment. Note that this statistic is computed using subjects' first stage contribution decisions, regardless of whether these were confirmed or withdrawn in the second stage and thus exclude 
any potential effects of selection (e.g., if the high-contributing groups may be more likely to agree to play the PGG). In the analysis of section 3.4 we will explore selection effects in more detail.

Inspection of the right panel of Figure 1 reveals that conditional participation has a dramatic impact on the distribution of contributions: the percentage of free-riders drops to $25 \%$; $40 \%$ of subjects contribute at least half of their endowment; and $24 \%$ contribute their full endowment to the public good. We use Mann-Whitney and Kolmogorov-Smirnov tests to formally compare contributions between the Conditional and Baseline treatments. In both cases the treatment differences are highly significant $(\mathrm{MW}: \mathrm{z}=3.475, \mathrm{p}=0.001$, two-tailed; KS: $\mathrm{D}=$ 0.309, $\mathrm{p}=0.003$, two-tailed; $\mathrm{n}=68$ per treatment).

In contrast, voluntary participation has only a negligible impact on cooperation when the participation decision is unconditional. Average contributions in the Unconditional treatment are $22 \%$ of endowment, exactly as in Baseline. The right panel of Figure 1 reveals that unconditional participation has two contrasting effects on contribution behavior. On the one hand, it somewhat increases the share of high contributions relative to Baseline (15\% of subjects in Unconditional contribute at least half of their endowment). On the other hand, it seems to encourage free-riding: in Unconditional half of subjects contribute zero tokens to the public good. However, these effects are small. In fact, we cannot detect statistically significant differences between Unconditional and Baseline using Mann-Whitney and Kolmogorov-Smirnov tests (MW: $\mathrm{z}=$ 0.641, $\mathrm{p}=0.522$, two-tailed; KS: $\mathrm{D}=0.088, \mathrm{p}=0.954$, two-tailed; $\mathrm{n}=68$ per treatment). Contributions are instead significantly different between Unconditional and Conditional, both using Mann-Whitney and Kolmogorov-Smirnov tests (MW: z = 3.800, p < 0.001, two-tailed; KS: $\mathrm{D}=0.309, \mathrm{p}=0.003$, two-tailed; $\mathrm{n}=68$ per treatment).

\subsection{A robustness treatment: Unconditional_High}

Overall, our results suggest that voluntary participation can promote cooperation and have a positive effect on public good provision. However, this positive effect is observed only when participation can be conditioned on the opponent's contribution decision. Unconditional participation does not seem to have bite in our setting as cooperation levels when voluntary participation is available are very similar to the case of forced participation. 
A potential reason why unconditional participation performs poorly in our setting is that the value we chose for the outside option payoff is too low to trigger a mechanism of assortative matching based on beliefs of cooperation. That is, when the value of the outside option payoff is low, even a pessimistic free-rider, who attaches a low probability to the event of meeting a cooperator, may find it profitable to self-select into cooperative groups. In fact, prima facie our data seem to support this conjecture. We observe very little selection in the Unconditional treatment as $86 \%$ of our subjects chose to take part in the PGG. Moreover, as noted in the previous sub-section, unconditional participation seems to increase the fraction of both high contributors and free-riders.

To address this issue, we conducted an additional treatment with unconditional participation, Unconditional_High. This treatment is identical to the original Unconditional treatment except that the outside option payoff was set at 70 points, halfway between the Nash equilibrium payoff level and the joint-payoff maximizing level. We recruited an additional 154 subjects for the Unconditional_High treatment across eight sessions, using the same subject pool, recruitment and procedures as in the other treatments. We observe substantial selection in Unconditional_High: only $50 \%$ of the subjects decided to take part in the PGG, whereas the remaining subjects chose to secure the outside option payoff. Overall, in fifty-eight of the seventy-seven groups at least one subject did not take part in the PGG. Hence, in Unconditional_High we observe contribution decisions from 38 subjects in total.

Figure 2 shows the average contribution level and the CDF of contributions in Unconditional_High. For ease of comparison, the figure also reproduces the average contribution levels and CDFs of the other three treatments, which were already shown in Figure 1. 


\section{Figure 2: Contributions to public good in Unconditional_High}
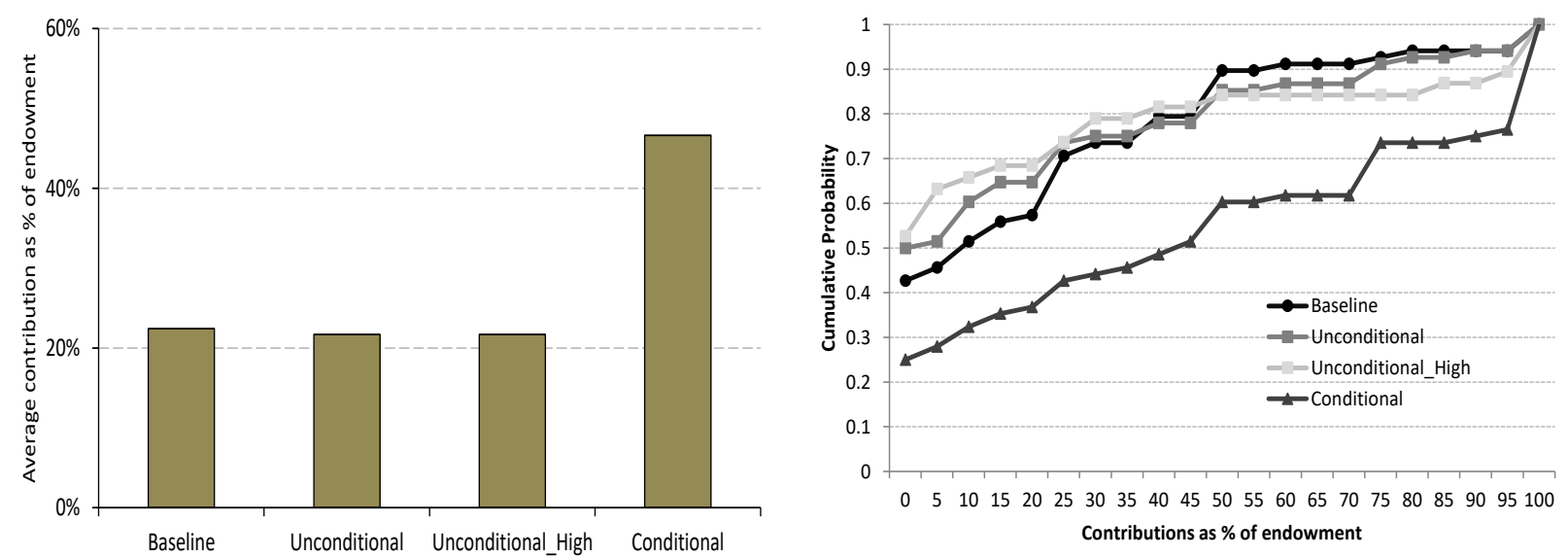

The substantially higher value of the outside option payoff does not improve the effectiveness of unconditional participation. As in Baseline and Unconditional, also in Unconditional_High subjects contribute on average about $22 \%$ of the endowment. Moreover, the right panel of Figure 2 shows that the distribution of contributions in Unconditional_High overlap substantially with those of Baseline and Unconditional. The figure also reinforces the impression that unconditional participation has two contrasting effects on contributions as it seems to encourage both more free-riding and more cooperation relative to Baseline. The fraction of full free-riders in Unconditional_High is 53\%. At the same time, $16 \%$ of subjects contribute at least half of their endowment to the public good, with $11 \%$ contributing the whole endowment. Overall, using Mann-Whitney and Kolmogorov-Smirnov tests, we do not find any significant differences between Unconditional_High and Baseline (MW: $\mathrm{z}=0.876, \mathrm{p}=0.381$, two-tailed; $\mathrm{KS}: \mathrm{D}=0.176, \mathrm{p}=0.439$, two-tailed; $\mathrm{n}=68$ in Baseline, $\mathrm{n}=38$ in Unconditional_High), or between Unconditional_High and Unconditional (MW: $\mathrm{z}=0.283, \mathrm{p}=0.777$, two-tailed; $\mathrm{KS}: \mathrm{D}=$ 0.117, $\mathrm{p}=0.893$, two-tailed; $\mathrm{n}=68$ in Unconditional, $\mathrm{n}=38$ in Unconditional_High

Unconditional_High). Contributions are instead significantly different between Unconditional_High and Conditional (MW: $\mathrm{z}=3.259, \mathrm{p}=0.001$, two-tailed; KS: $\mathrm{D}=0.352, \mathrm{p}=$ 0.005, two-tailed; $\mathrm{n}=68$ in Conditional, $\mathrm{n}=38$ in Unconditional_High).

Overall, these data point to the limits of a mechanism of assortative matching based on different beliefs of cooperation between cooperators and free-riders. In our original Unconditional treatment we observe a negligible effect of voluntary participation on cooperation, but we also observe limited evidence of sorting into the game. In contrast, we observe substantial 
selection in the Unconditional_High treatment. Yet, we again find no effect of voluntary participation on cooperation. In the next sub-section we look further into the reasons for the failure of unconditional participation as well as the reasons for the success of the conditional mechanism.

\subsection{The determinants of conditional and unconditional participation}

As argued above, a possible instance in which unconditional participation may affect cooperation through an assortative matching mechanism hinges on individuals suffering from a false consensus bias whereby cooperators are more optimistic than free-riders about the likelihood of meeting another cooperator. If this bias is sufficiently strong, and if subjects act on these biased beliefs when they decide whether to participate in the PGG, cooperators will be more likely than free-riders to self-select into the PGG. Within this framework, the limited effects of unconditional participation on cooperation may be explained by two different reasons. First, subjects in our experiment may not suffer from a false consensus bias. Alternatively, they could display a false consensus bias, but they may fail to act on their biased beliefs when deciding to enter the PGG.

Our data from the PD game allows us to explore these alternative explanations. We use choices in the role of second-mover in the PD game to classify subjects as "cooperators" (if they cooperated) or "free-riders" (if they defected). Across our four treatments, we classify $42 \%$ of our subjects as cooperators and $58 \%$ as free-riders. ${ }^{13}$ We use subjects' beliefs about others' behavior in the role of second-mover in the PD game to measure their optimism about the likelihood of interacting with a cooperator. On average, cooperators believe that $48 \%$ of the other subjects are also cooperators. In contrast, free-riders believe that only $31 \%$ of others are cooperators. This difference in beliefs is significant at the $1 \%$ level using a Mann-Whitney test ( $\mathrm{z}$ $=5.893, \mathrm{p}<0.001$, two-tailed; cooperators $\mathrm{n}=160$, free-riders $\mathrm{n}=222) .{ }^{14}$ Thus, in line with the existing experimental evidence, our subjects display a false consensus bias.

\footnotetext{
${ }^{13}$ The classification of types in the PD game correlates well with contribution behavior in the PGG. A regression of subjects' contributions in the PGG on PD type and treatment dummies shows that cooperators contribute about $14 \%$ more than free-riders and the difference in significant at the $1 \%$ level.

14 This result holds also if we focus on the Unconditional and Unconditional_High treatments only. Here, cooperators and free-riders believe that, respectively, $47 \%$ and $31 \%$ of the others are cooperators, and the difference is significant at the $1 \%$ level using a Mann-Whitney test $(\mathrm{z}=4.321, \mathrm{p}<0.001$, two-tailed; cooperators $\mathrm{n}=94$, freeriders $n=152$ ).
} 
We next use regression analysis to examine whether this bias in subjects' optimism about the prospects of meeting a cooperator affects their decision to participate in the PGG. Table 2 reports marginal effects from logit regressions of participation decisions of subjects in the Unconditional and Unconditional_High treatments. In all models the dependent variable assumes value 1 if a subject chooses to participate in the PGG, and 0 otherwise. In model I we use as regressor a dummy variable assuming value 1 if a subject is classified as a cooperator in the PD game, and 0 otherwise. In model II we use instead our measurement of subjects' optimism, defined as a subject's estimate of the fraction of other participants in the session that act as cooperators in the PD game (on a scale from 0 to 1). Note that the implicit assumption here is that a subject's beliefs about cooperation in the PD game are correlated with their beliefs about behavior in the PGG, which we did not elicit. In model III we include both the cooperator dummy and the optimism variable. In all models we also include a gender dummy (1 if subject is male), a dummy assuming value 1 if the subject studies Economics and 0 otherwise, and measurements of subjects' self-assessment of their risk attitudes (the SOEP general risk question) and trust attitudes (the WVS Trust question). ${ }^{15}$

The regressions show that there is little evidence in our data of sorting based on cooperativeness or beliefs of cooperativeness. Subjects' cooperativeness, as captured by the cooperator dummy, has virtually no impact on the decision to participate in the PGG (model I). Subjects' degree of optimism has somewhat more success in explaining participation decisions, as shown in model II: an increase in optimism by 10 percentage points increase the likelihood to enter the PGG by about $2 \%$, and the effect is insignificant $(\mathrm{p}=0.152)$. In model III we include both cooperativeness and optimism as explanatory variables, but neither reaches statistical significance at the $10 \%$ level. In fact, the cooperator dummy enters with a negative sign in the regression, indicating that, controlling for their degree of optimism, cooperators are actually less likely to enter the PGG than free-riders. ${ }^{16}$ None of the other regressors are statistically significant in any of the models except the measurement of risk attitudes, which is positively related to the decision to participate.

\footnotetext{
${ }^{15}$ Note, however, that the variables measuring risk and trust attitudes may not be entirely exogenous since they may to some extent reflect subjects' ex-post rationalizations of their behavior in the experiment (e.g., a subject who has self-selected into the PGG may be more likely to perceive him/herself as risk loving in the questionnaire).

${ }^{16} \mathrm{We}$ also ran an additional regression where we interacted the cooperator dummy with the optimism variable. The interaction term and the cooperator and optimism variables are all statistically insignificant in this regression.
} 


\section{Table 2: Logit regressions of participation decisions - Unconditional treatments}

\begin{tabular}{l|ccc}
\hline \hline & I & II & III \\
\hline Cooperator in PD game & 0.003 & -- & -0.024 \\
& $(0.066)$ & -- & $(0.069)$ \\
Optimism in PD game & -- & 0.167 & 0.179 \\
& -- & $(0.117)$ & $(0.121)$ \\
1 if male & 0.037 & 0.029 & 0.027 \\
& $(0.064)$ & $(0.065)$ & $(0.065)$ \\
1 if studies Economics & 0.039 & 0.060 & 0.059 \\
& $(0.080)$ & $(0.080)$ & $(0.080)$ \\
SOEP risk loving & $0.066^{* * *}$ & $0.066^{* * *}$ & $0.066^{* * *}$ \\
& $(0.015)$ & $(0.015)$ & $(0.015)$ \\
WVS high trust & 0.047 & 0.036 & 0.036 \\
& $(0.064)$ & $(0.065)$ & $(0.065)$ \\
\hline N & 246 & 246 & 246 \\
\hline \hline & Note: Marginal effects of logit regressions, standard errors in parentheses. In all models the \\
dependent variable assumes value 1 if a subject chose to participate in the PGG and 0 & \\
otherwise. Significance levels: *** 1\%.
\end{tabular}

Overall, this analysis shows that, while our subjects do display a false consensus bias, they seem not to act on their biased beliefs about others' cooperativeness when deciding to participate in the PGG. This explains the limited effectiveness of unconditional participation in our experiment.

We next turn to subjects' participation decisions in the Conditional treatment. First, we note that the decision to withdraw participation is made quite frequently in our experiment. In $76 \%$ of groups at least one subject decided to withdraw their participation from the PGG. This decision is predominantly taken when subjects contribute more than their opponent: when this happens, subjects choose to withdraw participation in $80 \%$ of cases. On the contrary, subjects confirm their participation in the PGG in $90 \%$ of cases where their contributions are the same or lower than that of their opponent. This suggests that withdrawal decisions are mainly used to retaliate against free-riding. In most of cases withdrawals are also materially beneficial for the subject who makes that decision because the payoff of withdrawing participation exceeds that of participating in the PGG. However, we also have 7 cases where the payoff of non-participation is lower than that of participation, and in 2 of these (29\%) the subject decided not to participate.

We analyze these patterns of withdrawal decisions more formally in Table 3, where we report marginal effects of a logit regression of participation decisions in the Conditional 
treatment. The dependent variable assumes value 1 if a subject chose to participate in the PGG, and 0 otherwise. We use three specifications. In model I we include a variable measuring the amount contributed by the other subject in the group. In model II we add a subject's own contribution as a regressor. Finally, in model III we use a variable measuring the difference between subject $i$ 's contribution and the contribution of the other subject $j$. All models also include the cooperator dummy and the control variables used in Table 2.

Table 3: Logit regressions of participation decisions - Conditional treatment

\begin{tabular}{l|ccc}
\hline \hline & I & II & III \\
\hline Subject $i$ 's own contribution & - & $-0.033^{* *}$ & - \\
Subject $j$ 's contribution & $0.072^{* * *}$ & $0.070^{* * *}$ & - \\
& $(0.016)$ & $(0.020)$ & $-0.069^{* * * *}$ \\
Difference between $i$ 's and $j$ 's contributions & & - & $(0.024)$ \\
& - & & 0.104 \\
Cooperator in PD game & 0.020 & 0.091 & $(0.148)$ \\
& $(0.147)$ & $(0.103)$ & 0.086 \\
1 if male & 0.125 & 0.034 & $0.154)$ \\
& $(0.164)$ & $(0.120)$ & 0.242 \\
1 if studies Economics & 0.074 & 0.098 & $(0.171)$ \\
& $(0.161)$ & $(0.088)$ & -0.064 \\
SOEP risk loving & $-0.067^{*}$ & -0.036 & $(0.041)$ \\
& $(0.037)$ & $(0.034)$ & -0.052 \\
WVS high trust & 0.116 & 0.034 & $(0.173)$ \\
\hline $\mathrm{N}$ & $(0.161)$ & $(0.111)$ & 68 \\
\hline \hline
\end{tabular}

Note: Marginal effects of logit regressions, robust standard errors in parentheses, adjusted for intragroup correlation (PGG groups are used as independent clustering units). The dependent variable assumes value 1 if subject $i$ chose to participate in the PGG and 0 otherwise. Significance levels: *** $1 \% ; * * 5 \% ; * 10 \%$.

The regressions confirm that participation is strongly influenced by subjects' decisions in the contribution stage. Model I and II show that the likelihood of participating in the PGG is positively related to the other subject's contribution and negatively related to the subject's own contribution. ${ }^{17}$ Model III shows that this polarized impact of other's and own contributions on participation can be described as an effect of the differences in contributions: a one-token difference between contributions of the two players decreases the likelihood of participation by

\footnotetext{
${ }^{17}$ This effect is robust to alternative specifications, e.g. if we drop the PD cooperator dummy (since it is correlated with own contributions in the PGG).
} 
about $7 \%$. The effect is statistically significant at the $1 \%$ level. Subjects' cooperativeness does not explain the decision to participate in the PGG. None of the other explanatory variables have a systematic effect on participation decisions.

\subsection{Earnings across treatments}

We conclude this section with an analysis of earnings across treatments. In Baseline subjects on average earn 64.49 points, somewhat more than the Nash equilibrium outcome of 60 points, but substantially less than the joint-payoff maximizing level of 80 points. Computing efficiency as attained earnings in excess of the zero-contribution Nash equilibrium earnings as a percentage of maximum possible gains, we find that in Baseline this is equal to $\frac{(64.49-60)}{(80-60)}=22.5 \%$. If we consider earnings conditional on both subjects in the group agreeing to participate in the game, we find that conditional participation has a substantial beneficial effect compared to Baseline. The average earnings of the subjects who agreed to play the PGG in the Conditional treatment are 76.38 points (an efficiency of $81.9 \%$ ), and earnings in this treatment are significantly different from Baseline (Mann-Whitney test: $\mathrm{z}=4.032, \mathrm{p}<0.001$, two-tailed; $\mathrm{n}=34$ in Baseline, $\mathrm{n}=8$ in Conditional). ${ }^{18}$ Thus, conditional participation leads to a gain in efficiency of $81.9 \%$ $22.5 \%=59.4 \%$ relative to Baseline. This efficiency gain reflects both a potential selection effect (the high-contributing groups may be more likely to agree to play the PGG) and the effect of the threat-value of voluntary participation. To disentangle the two, we also compute average earnings of all subjects based on their contributions in the PGG, regardless of their participation decisions, thus removing selection effects. We find that average earnings are 69.32 points (an efficiency of 46.6\%), and earnings are significantly different from Baseline (Mann-Whitney test: $\mathrm{z}=3.479, \mathrm{p}$ $<0.001$, two-tailed; $\mathrm{n}=34$ per treatment). This suggests that the threat-value of voluntary participation alone accounts for $46.6 \%-22.5 \%=24.1 \%$ out of the $59.4 \%$ efficiency gain of Conditional relative to Baseline.

In the treatments with unconditional participation, average earnings (conditional on participation) are instead 64.34, both in Unconditional and Unconditional_High (an efficiency of 21.7\%). In both cases, earnings are not significantly different from Baseline (Mann-Whitney

\footnotetext{
${ }^{18}$ Note that tests on earnings are conducted at the pair level rather than at the subject level because subjects' earnings within a pair are not independent from each other.
} 
tests: Baseline vs. Unconditional, $\mathrm{z}=0.179, \mathrm{p}=0.858$, two-tailed, $\mathrm{n}=34$ per treatment; Baseline vs. Unconditional_High, $\mathrm{z}=0.252, \mathrm{p}=0.801$, two-tailed, $\mathrm{n}=34$ in Baseline, $\mathrm{n}=19$ in Unconditional_High). These results confirm the relative advantage of conditional versus unconditional participation in our setting.

Of course, voluntary (non-)participation can imply substantial costs if subjects choose to forgo positive levels of public good provision and prefer to secure the outside option payoff instead. To examine this, we also compute realized earnings in the Conditional and Unconditional treatments as equal to subjects' PGG earnings if both subjects in the group agreed to participate in the game, and to the outside option payoff otherwise. ${ }^{19}$ Average realized earnings in the Conditional treatment are 64.62 points (an efficiency of 23.1\%), and we do not find significantly differences relative to Baseline (Mann-Whitney test: $\mathrm{z}=0.556, \mathrm{p}=0.578$, twotailed; $\mathrm{n}=34$ per treatment). Thus, the frequent decisions to withdraw participation reduce the positive effects of voluntary participation. Average realized earnings in Unconditional are equal to 63.47 points (an efficiency of 17.4\%). Again, we do not detect significant differences in earnings relative to Baseline (Mann-Whitney test: $\mathrm{z}=0.908, \mathrm{p}=0.364$, two-tailed; $\mathrm{n}=34$ in Baseline, $\mathrm{n}=46$ in Unconditional).

This latter set of results should be taken with caution as they are inevitably sensitive to the details of our experimental implementation, such as the specific value of the outside option payoff, or the fact that we implemented a one-shot version of the PGG rather than a repeated version of the game. ${ }^{20}$ In practice (as well as in the theoretical models discussed in the Introduction) the value of participation is partly determined endogenously, and may depend, among other things, on the expected time horizon of the interaction and individuals' discount factor, and all this may affect the efficiency consequences of the conditional mechanism. Nevertheless, our findings point to a potential limitation of this mechanism. Subjects frequently withdraw participation when this option is available even when doing so reduces joint payoffs (this actually occurs in $75 \%$ of cases). As a consequence, when one accounts for the costs of

\footnotetext{
${ }^{19}$ In doing this we only focus on our three original treatments and we do not include Unconditional_High in the analysis. The artificially high value of the outside option payoff in this treatment implies that not participating in the PGG is unlikely to lead to efficiency losses.

${ }^{20}$ There is evidence that retaliation mechanisms that are socially inefficient in the short-run may nonetheless lead to long-run benefits (e.g., Gächter et al., 2008).
} 
withdrawals, realized earnings are not significantly different between settings with forced and voluntary participation.

\section{Conclusions}

Our study has shed light on the effects of voluntary participation on cooperation. In a one-shot two-person public goods game, we have found that allowing players to voluntarily take part in the game can have a beneficial effect on contributions relative to a setting where participation is forced. However, our study also shows that voluntary participation is most effective when subjects are let free to reject (potential) partnerships they are not satisfied with. This allows cooperators to shield themselves from exploitation by free-riders, as the threat of costly rejections is powerful in disciplining free-riding and fostering higher contributions.

By contrast, voluntary participation does not foster cooperation when it operates through a mechanism of assortative matching driven by false consensus bias: if cooperators are more optimistic than free-riders about the prospects of meeting other cooperators, then voluntary participation may facilitate a process of self-selection whereby cooperators participate into the public goods game and free-riders stay out. In the experiment we do find evidence of a false consensus bias, but we also find that subjects do not seem to act upon their biased beliefs when they decide whether to participate in the public goods game. Thus the participation decisions of cooperators and free-riders are not statistically distinguishable from each other. As a consequence, this mechanism is not successful in fostering public good provision.

While the specific assortative matching mechanism based on false consensus bias that we have studied here does not seem to be successful in fostering cooperation, this is not the only mechanism through which voluntary participation may trigger assortative matching, and alternative mechanisms may be more successful in fostering cooperation. For instance, Aimone et al. (2013) study a modified public goods game where groups are formed based on subjects' willingness to sacrifice returns from private investments. They find that cooperators are more willing to sacrifice private investments than free-riders, which leads to assortative matching and increased public good provision.

Moreover, in natural environments individuals may rely on communication and other observable characteristics about their potential interaction partners to predict their cooperative inclination and hence decide whether or not to start a partnerships with them. Some authors have 
argued that this may also lead to assortative matching of cooperative types (e.g., Frank, 1987; 1988; Amann and Yang, 1998). However, the empirical evidence suggests that individuals are only to some extent able to predict whether others are likely to cooperate. Belot et al. (2012), for example, ask subjects in an experiment to watch clips of a prisoner's dilemma game played on a TV show, and then predict the extent to which TV show contestants are likely to cooperate. While subjects estimate a higher likelihood of cooperation for cooperators than free-riders, the difference is small (7 percentage points). In line with this, van den Assem et al. (2011) find that contestants in a related TV show do not predict well the cooperative behavior of their opponents.

Though the two mechanisms studied in our paper cannot be applied to non-excludible public goods such as clean air or national security, there are several naturally occurring settings in which goods are publicly provided only to members who voluntarily participate in such cooperative endeavors. Typical real-world examples are associations, clubs, workplaces, partnerships, and the like, in which individuals may have the freedom to join in, or opt out from, participating in the provision of (local) public goods. ${ }^{21}$

In those and similar instances, cooperation among individuals is crucial while it is often characterized by intrinsic fragility due to the conflict between individual incentives and social optimal actions. Despite its fragility, in naturally occurring environments, a large variety of mechanisms are at work to foster cooperative outcomes. Scholars have explored a significant number of mechanisms conducive to cooperation. Our study has focused on a fundamental mechanism, voluntary participation, in the attempt to uncover useful stylized patterns for the design of institutions aimed at overcoming under-provision of public goods. The development of such institutions is an intellectual journey that will require the understanding of "how diverse polycentric institutions help or hinder the (...) levels of cooperation of participants, and the achievement of more effective, equitable, and sustainable outcomes at multiple scales" (Ostrom, 2010, p. 665); such a journey seems far from reaching its end.

\footnotetext{
${ }^{21}$ However, note that in our two-player experiment withdrawal of participation by one player effectively means the automatic exclusion of the other. It may be interesting to extend our design in order to adapt the two mechanisms of participation to a setting with more than two players.
} 


\section{REFERENCES}

Ahn, T.K., R.M. Isaac, and T.C. Salmon. 2008. Endogenous group formation. Journal of Public Economic Theory 10(2), 171-194.

Ahn, T.K., R.M. Isaac, and T.C. Salmon. 2009. Coming and going: Experiments on endogenous group sizes for excludable public goods. Journal of Public Economics 93(1-2), 336-351.

Aimone, J.A., L.R. Iannaccone, M.D. Makowsky, and J. Rubin. 2013. Endogenous Group Formation via Unproductive Costs. The Review of Economic Studies 80(4), 1215-1236.

Aktipis, C.A. 2004. Know when to walk away: contingent movement and the evolution of cooperation. Journal of Theoretical Biology 231(2), 249-260.

Amann, E., and C.-L. Yang. 1998. Sophistication and the persistence of cooperation. Journal of Economic Behavior \& Organization 37(1), 91-105.

van den Assem, M.J., D. van Dolder, and R.H. Thaler. 2011. Split or Steal? Cooperative Behavior When the Stakes Are Large. Management Science 58(1), 2-20.

Belot, M., V. Bhaskar, and J. van de Ven. 2012. Can Observers Predict Trustworthiness? Review of Economics and Statistics 94(1), 246-259.

Blanco, M., D. Engelmann, A.K. Koch, and H.-T. Normann. 2010. Belief elicitation in experiments: is there a hedging problem? Experimental Economics 13(4), 412-438.

Blanco, M., D. Engelmann, A.K. Koch, and H.-T. Normann. 2014. Preferences and beliefs in a sequential social dilemma: a within-subjects analysis. Games and Economic Behavior 87, $122-135$.

Blanco, M., D. Engelmann, and H.-T. Normann. 2011. A Within-Subject Analysis of OtherRegarding Preferences. Games and Economic Behavior 72(2), 321-338.

Camerer, C.F. 2003. Behavioral game theory. Princeton: Princeton University Press.

Cason, T.N., T. Saijo, and T. Yamato. 2002. Voluntary Participation and Spite in Public GoodProvision Experiments: An International Comparison. Experimental Economics 5, 133-153.

Cason, T.N., T. Saijo, T. Yamato, and K. Yokotani. 2004. Non-excludable public good experiments. Games and Economic Behavior 49(1), 81-102.

Charness, G., and M. Dufwenberg. 2006. Promises and partnership. Econometrica 74(6), 15791601.

Charness, G., and B. Grosskopf. 2001. Relative payoffs and happiness: an experimental study. Journal of Economic Behavior \& Organization 45(3), 301-328.

Charness, G., and C.-L. Yang. 2014. Starting small toward voluntary formation of efficient large groups in public goods provision. Journal of Economic Behavior \& Organization 102, 119-132.

Cinyabuguma, M., T. Page, and L. Putterman. 2005. Cooperation under the threat of expulsion in a public goods experiment. Journal of Public Economics 89(8), 1421-1435. 
Cubitt, R.P., M. Drouvelis, and S. Gächter. 2011. Framing and free riding: emotional responses and punishment in social dilemma games. Experimental Economics 14(2), 254-272.

Dal Bó, P. 2005. Cooperation under the shadow of the future: Experimental evidence from infinitely repeated games. American Economic Review 95(5), 1591-1604.

Dietz, T., E. Ostrom, and P.C. Stern. 2003. The Struggle to Govern the Commons. Science 302(5652), 1907-1912.

Dohmen, T.J., A. Falk, D. Huffman, U. Sunde, J. Schupp, and G.G. Wagner. 2011. Individual Risk Attitudes: Measurement, Determinants, and Behavioral Consequences. Journal of the European Economic Association 9(3), 522-550.

Dufwenberg, M., S. Gächter, and H. Hennig-Schmidt. 2011. The framing of games and the psychology of play. Games and Economic Behavior 73(2), 459-478.

Ehrhart, K.-M., and C. Keser. 1999. Mobility and Cooperation: On the Run. CIRANO Working Paper 99s-24, URL: www.cirano.qc.ca/pdf/publication/99s-24.pdf.

Engelmann, D., and M. Strobel. 2000. The false consensus effect disappears if representative information and monetary incentives are given. Experimental Economics 3(3), 241-260.

Engelmann, D., and M. Strobel. 2012. Deconstruction and reconstruction of an anomaly. Games and Economic Behavior 76(2), 678-689.

Fehr, E., and S. Gächter. 2000. Cooperation and punishment in public goods experiments. American Economic Review 90(4), 980-994.

Fehr, E., and K.M. Schmidt. 1999. A theory of fairness, competition, and cooperation. Quarterly Journal of Economics 114(3), 817-68.

Fischbacher, U. 2007. z-Tree: Zurich toolbox for ready-made economic experiments. Experimental Economics 10(2), 171-178.

Fischbacher, U., S. Gächter, and S. Quercia. 2012. The behavioral validity of the strategy method in public good experiments. Journal of Economic Psychology 33(4), 897-913.

Frank, R.H. 1987. If Homo Economicus Could Choose His Own Utility Function, Would He Want One with a Conscience? The American Economic Review 77(4), 593-604.

Frank, R.H. 1988. Passion Within Reason. The Strategic Role of the Emotions. New York: W.W. Norton \& Company.

Fujiwara-Greve, T., and M. Okuno-Fujiwara. 2009. Voluntarily Separable Repeated Prisoner's Dilemma. The Review of Economic Studies 76(3), 993-1021.

Gächter, S., and B. Herrmann. 2009. Reciprocity, culture, and human cooperation: Previous insights and a new cross-cultural experiment. Philosophical Transactions of the Royal Society B - Biological Sciences 364(1518), 791-806.

Gächter, S., B. Herrmann, and C. Thöni. 2004. Trust, voluntary cooperation, and socio-economic background: survey and experimental evidence. Journal of Economic Behavior \& Organization 55(4), 505-531. 
Gächter, S., D. Nosenzo, E. Renner, and M. Sefton. 2012. Who Makes A Good Leader? Cooperativeness, Optimism And Leading-By-Example. Economic Inquiry 50(4), 953-967.

Gächter, S., E. Renner, and M. Sefton. 2008. The long-run benefits of punishment. Science 322, 1510.

Greiner, B. 2015. Subject pool recruitment procedures: organizing experiments with ORSEE. Journal of the Economic Science Association 1(1), 114-125.

Hauk, E. 2003. Multiple Prisoner's Dilemma Games with(out) an Outside Option: an Experimental Study. Theory and Decision 54(3), 207-229.

Heijden, E. van der, J. Nelissen, and J. Potters. 2007. Opinions on the Tax Deductibility of Mortgages and the Consensus Effect. De Economist 155, 141-159.

Izquierdo, L.R., S.S. Izquierdo, and F. Vega-Redondo. 2014. Leave and let leave: A sufficient condition to explain the evolutionary emergence of cooperation. Journal of Economic Dynamics and Control 46, 91-113.

Izquierdo, S.S., L.R. Izquierdo, and F. Vega-Redondo. 2010. The option to leave: Conditional dissociation in the evolution of cooperation. Journal of Theoretical Biology 267(1), 76-84.

Keser, C., and C. Montmarquette. 2011. Voluntary versus Enforced Team Effort. Games 2(3), 277-301.

Lin, J.Y. 1990. Collectivization and China's Agricultural Crisis in 1959-1961. Journal of Political Economy 98(6), 1228-1252.

Macy, M.W., and J. Skvoretz. 1998. The Evolution of Trust and Cooperation between Strangers: A Computational Model. American Sociological Review 63(5), 638-660.

Maier-Rigaud, F.P., P. Martinsson, and G. Staffiero. 2010. Ostracism and the provision of a public good: experimental evidence. Journal of Economic Behavior \& Organization 73(3), 387-395.

My, K., and B. Chalvignac. 2010. Voluntary participation and cooperation in a collective-good game. Journal of Economic Psychology 31(4), 705-718.

Offerman, T., J. Sonnemans, and A. Schram. 1996. Value Orientations, Expectations and Voluntary Contributions in Public Goods. Economic Journal 106, 817-845.

Olson, M. 1965. The logic of collective action. Cambridge: Harvard University Press.

Oosterbeek, H., R. Sloof, and G. van de Kuilen. 2004. Cultural Differences in Ultimatum Game Experiments: Evidence from a Meta-Analysis. Experimental Economics 7(2), 171-188.

Orbell, J., and R.M. Dawes. 1991. A 'Cognitive Miser' Theory of Cooperators' Advantage. The American Political Science Review 85(2), 515-528.

Orbell, J.M., and R.M. Dawes. 1993. Social Welfare, Cooperators' Advantage, and the Option of Not Playing the Game. American Sociological Review 58(6), 787-800.

Ostrom, E. 2010. Beyond Markets and States: Polycentric Governance of Complex Economic Systems. American Economic Review 100(3), 641-72. 
Page, T., L. Putterman, and B. Unel. 2005. Voluntary association in public goods experiments: Reciprocity, mimicry, and efficiency. Economic Journal 115, 1032-1052.

Rand, D.G., and M.A. Nowak. 2013. Human cooperation. Trends in Cognitive Sciences 17(8), 413-425.

Riedl, A., and A. Ule. 2002. Exclusion and cooperation in social network experiments. Unpublished Paper, CREED, URL: http://citeseerx.ist.psu.edu/viewdoc/download?doi=10.1.1.470.7016\&rep=rep1\&type=pdf.

Ross, L., D. Greene, and P. House. 1977. The 'false consensus effect': An egocentric bias in social perception and attribution processes. Journal of Experimental Social Psychology 13(3), 279-301.

Roth, A.E., and J.K. Murnighan. 1978. Equilibrium behavior and repeated play of the prisoner's dilemma. Journal of Mathematical Psychology 17(2), 189-198.

Schumacher, H. 2013. Imitating cooperation and the formation of long-term relationships. Journal of Economic Theory 148(1), 409-417.

Sefton, M., R. Shupp, and J.M. Walker. 2007. The effect of rewards and sanctions in provision of public goods. Economic Inquiry 45(4), 671-690.

Selten, R., and A. Ockenfels. 1998. An experimental solidarity game. Journal of Economic Behavior \& Organization 34(4), 517-539.

Walker, J.M., and M.A. Halloran. 2004. Rewards and sanctions and the provision of public goods in one-shot settings. Experimental Economics 7(3), 235-247.

Wilson, A., and H. Wu. 2017. At-will Relationships: How An Option To Walk Away Affects Cooperation And Efficiency. Games and Economic Behavior 102, 487-507. 


\section{ONLINE SUPPLEMENT TO \\ "The EFFECT OF Voluntary PARTiCipation ON COOPERATION" By Daniele Nosenzo and Fabio Tufano}

In Appendix A we present predictions for the Baseline, Unconditional and Conditional treatment for the model of inequity aversion of Fehr and Schmidt (1999)

In Appendix B we present the instructions used in the experiments. The preliminary instructions and instructions for Part 1 were common to all treatments. The instructions for Part 2 differed across treatments and we include differences in brackets. 


\section{APPENDIX A: INEQUALITY AVERSION AND EQUILIBRIUM CONTRIBUTIONS}

Suppose players have Fehr-Schmidt preferences as defined in the main text. In Baseline, material payoffs are given by:

$$
\pi_{i}=20-c_{i}+\frac{2}{3} \cdot\left(c_{i}+c_{j}\right)
$$

where $c_{i} \in\{0,1, \ldots, 20\}$ denotes player $i$ 's contribution.

Suppose each player contributes $c$ tokens to the public good. Then player $i$ gets an utility of $U_{i}=20-c+$ $\frac{4}{3} c=20+\frac{1}{3} c$.

If player $i$ were to unilaterally increase her contribution her material payoff would fall, she would incur disutility from disadvantageous inequality vis-à-vis the other player. Thus it is not possible for player $i$ to increase her utility by increasing contributions beyond $c$.

If player $i$ were to unilaterally decrease her contribution by $t$ units her utility would be $U_{i}=20-c+t+$

$\frac{4}{3} c-\frac{2}{3} t-t \beta_{i}$. Thus the reduction in contribution changes utility by $\Delta U_{i}=t-\frac{2}{3} t-t \beta_{i}=t\left(\frac{1}{3}-\beta_{i}\right)$. This is positive for small $\beta_{i}$ and negative for large $\beta_{i}$. The critical value of $\beta_{i}$ where the increase is zero is $\beta_{i}^{*}=\frac{1}{3}$. Thus if the two players have $\beta_{i} \geq \beta_{i}^{*}$ any symmetric contribution profile is an equilibrium.

Consider now the Unconditional treatment. Suppose that both players have $\beta_{i} \geq \beta_{i}^{*}$ and that they know each other's preferences. As shown above, in the subgame where subjects make a contribution decision in the PGG, any symmetric contribution profile is an equilibrium. Suppose that players select an equilibrium with positive contributions, yielding an equilibrium payoff $\hat{\pi}_{i}$ strictly greater than 61 points per player. ${ }^{1}$ By replacing this subgame with its subgame perfect equilibrium value, we obtain the following reduced game.

Table A1: Reduced Unconditional game $-\boldsymbol{\beta}_{i} \geq \boldsymbol{\beta}_{i}^{*}$

\begin{tabular}{lcc}
\hline & \multicolumn{2}{c}{ PLAYER 2 } \\
\cline { 2 - 3 } PLAYER 1 & Participate & Do not participate \\
\hline Participate & $\hat{\pi}_{1}, \hat{\pi}_{2}$ & 61,61 \\
Do not participate & 61,61 & 61,61 \\
\hline \hline
\end{tabular}

The reduced game has two pure-strategy equilibria, one involving mutual non-participation and one involving mutual participation. Moreover, participation is a weakly dominant strategy. Thus, if we refine the equilibrium set by requiring that players do not use weakly dominated strategies, only the equilibrium with mutual participation survives. This shows that unconditional participation can have a positive effect on contributions with other-regarding players.

\footnotetext{
${ }^{1}$ This requires $c>1$.
} 
However, if one or both players have $\beta_{i}<\beta_{i}^{*}$, then unconditional participation has no positive effect on contributions. To see this, note that in the subgame where subjects make a contribution decision in the PGG, the only equilibrium now involves zero contributions and a payoff of 60 points per player. Thus, the corresponding reduced game is:

Table A2: Reduced Unconditional game - at least one player $\beta_{i}<\beta_{i}^{*}$

\begin{tabular}{lcc}
\hline \hline & \multicolumn{2}{c}{ PLAYER 2 } \\
\cline { 2 - 3 } PLAYER 1 & Participate & Do not participate \\
\hline Participate & 60,60 & 61,61 \\
Do not participate & 61,61 & 61,61 \\
\hline \hline
\end{tabular}

As discussed in the main text, here the only equilibrium where players do not use weakly dominated strategies is the one involving mutual non-participation.

Finally, consider the Conditional treatment. Suppose that both players are sufficiently averse to disadvantageous inequality and have $\alpha_{i} \geq \alpha_{i}^{*}=5.67$. For this level of aversion to disadvantageous inequality, player $i$ prefers nonparticipation and an outside payoff of 61 to participating in any game with contribution profiles where $i$ 's own contribution is one token higher than $j$ 's contribution. ${ }^{2}$

Given this, the logic to construct the equilibria is similar to that presented in the main text for self-interested players. Consider the subgames following the contribution stage. There are three cases. First, in all subgames following asymmetric contribution profiles, any equilibrium involves non-participation and a payoff of 61 for each player because inequality-averse players have a weakly dominant strategy (within the subgame) not to participate. Second, in the subgames where players' contributions are symmetric and larger than 1, participating in the PGG is a weakly dominant strategy (within the subgame) for both players. Using weak dominance as a refinement, we select the equilibrium with mutual participation in these subgames. Finally, in the subgames where players' contributions are 0 or 1, mutual participation would lead to payoffs of 60 or 61 per player, respectively. In these subgames, any equilibrium involves a payoff of 61 per player (respectively because non-participation is weakly dominant, or because both participation and non-participation lead to a payoff of 61).

By replacing each subgame with its subgame perfect equilibrium value, we obtain a reduced game where any symmetric contribution profile is an equilibrium. In the symmetric equilibrium with zero contributions both players earn a PGG payoff lower than 61. Thus, in the corresponding subgame perfect equilibria of the extended game players withdraw participation from the PGG and the public good is not provided. In the remaining equilibria, both players earn at least 61 points from the PGG and thus they confirm their participation in the PGG in the

\footnotetext{
${ }^{2}$ When $\alpha_{i}=5.67$, player $i$ prefers not to participate even when player $i$ contributes 20 and player $j$ contributes 19 . Confirming participation would lead to a payoff of 78 for player $i$ and a payoff of 81 to player $j$. The utility of player $i$ from participation is thus: $78-5.67(81-78)=60.99$ and, thus, player $i$ prefers to withdraw participation.
} 
corresponding subgame perfect equilibria of the extended game. Thus, relative to the case of self-interested preferences, higher contribution levels can be sustained in equilibrium when players are sufficiently averse to disadvantageous inequality.

Which contribution levels can actually be sustained in equilibrium depends on the degree of aversion to disadvantageous inequality. When $\alpha_{i} \geq \alpha_{i}^{*}=5.67$, as we have assumed above, any symmetric contribution profile, including the one with full contributions, can be sustained in equilibrium. However, this level of aversion to disadvantageous inequality may be very high (Blanco et al., 2011, find that only $13 \%$ of subjects have an $\alpha_{i} \geq 4.5$ ). Even for smaller level of aversion to disadvantageous inequality, one can sustain contribution profiles where players contribute more than 2 tokens (the profile that can sustained with self-interested preferences). For example, when $\alpha_{i} \geq 1$ contributions up to 6 tokens per player can be sustained in equilibrium since a player $i$ with $\alpha_{i} \geq 1$ would prefer non-participation with an outside payoff of 61 to participating in any game with a contribution profile where $i$ contributes (up to) 6 tokens and $j$ undercuts $i$ 's contribution by one token. More generally, the higher the degree of aversion to disadvantageous inequality, the higher the contribution level that can be sustained in equilibrium. 


\section{APPENDIX B - EXPERIMENT INSTRUCTIONS}

\section{PRELIMINARY INSTRUCTIONS (common to all treatments)}

Welcome! You are about to take part in a decision-making experiment. This experiment is run by the Centre for Decision Research and Experimental Economics and has been financed by various research foundations.

There are other people in this room, who are also participating in this experiment. Everyone is participating for the first time, and all participants are reading the same instructions. It is important that you do not communicate with any of the other participants during the experiment. If you have a question at any time, raise your hand and an experimenter will come to your desk to answer it.

This experiment consists of two parts: Part 1 and Part 2.

In each part of the experiment you will be asked to make one or more decisions, and will have a chance to earn money. Decisions that will be made in one part of the experiment will not affect decisions or earnings in the other part of the experiment.

You will be informed of any outcome (including your earnings) from Part 1 and Part 2 of the experiment only once everyone in the room has completed Part 2. Therefore everyone will make their decisions in Part 2 without knowing any outcome from Part 1.

Only one part of the experiment will be taken into account in determining your final earnings from today's experiment. At the end of Part 2, we will toss a fair coin. If the coin lands heads all participants in today's experiment will be paid according to their earnings from Part 1. If the coin lands tails all participants in today's experiment will be paid according to their earnings from Part 2. Your earnings will be paid out to you in private and in cash.

Shortly, you will receive detailed instructions about Part 1 of the experiment. You will receive detailed instructions about Part 2 once everyone in the room has completed Part 1.

If you have a question now, please raise your hand and an experimenter will come to your desk to answer it. 
Part 1 - Instructions (common to all treatments)

\section{General}

In this part of the experiment you will be paired with one other person, randomly selected from the participants in this room. At the end of Part 1 the pair will be dissolved, and you will not be matched with this person again during this experiment.

Your earnings in Part 1 will only depend on your decisions and the decisions of the person you are paired with. All decisions are made anonymously and you will not learn the identity of the person you are paired with.

Your earnings in Part 1 will be calculated in points. At the end of Part 1 your point earnings will be converted into cash at the exchange rate of 15 pence per point. If Part 1 is selected for payment, you will be paid this amount in private and in cash at the end of the experiment.

\section{The Decision Situation}

Your earnings in Part 1 of the experiment will depend on decisions made in the following decision situation. You will be in this decision situation only once (i.e. there is only one period in Part 1 of the experiment).

There are two people involved in the decision situation: 'Person A' and 'Person B'. Person A can choose between two options: IN or OUT.

If Person A chooses OUT, Person B has no choice to make, and both Person A and Person B earn 50 points each.

If Person A chooses IN, then Person B has a choice between two options: LEFT or RIGHT. If Person B chooses LEFT, both Person A and Person B earn 70 points each. If Person B chooses RIGHT, Person A earns 35 points and Person B earns 85 points.

The decision situation is illustrated in the Figure below.

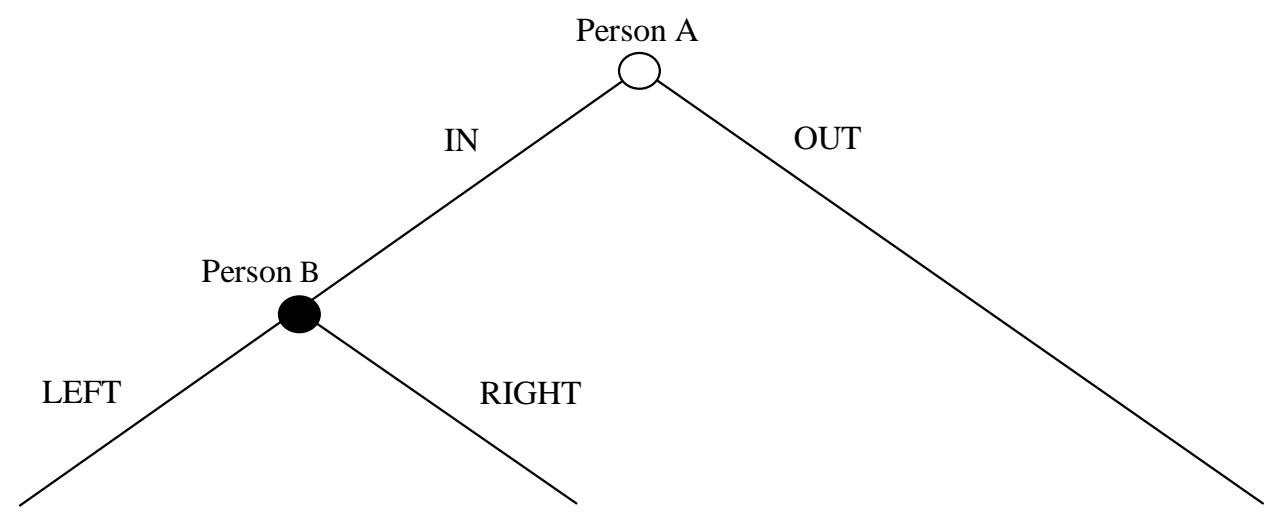

Person A earns $\mathbf{7 0}$ points

Person A earns $\mathbf{3 5}$ points

Person A earns $\mathbf{5 0}$ points Person B earns 70 points

Person B earns 85 points

Person B earns $\mathbf{5 0}$ points 


\section{How You Make Decisions}

You will make decisions on the computer by completing a screen. The attached sheet shows what the screen will look like. We want to know what you would do in the role of Person A and what you would do in the role of Person B. Thus you will be prompted to make decisions in both roles. Only after you have made your decisions will the computer determine your actual role, "Person A" or "Person B", and this will determine your relevant decisions for calculating earnings. The computer will select roles randomly: there is a 50\% chance you will be Person A and the person you are paired with will be Person B, and a 50\% chance you will be Person B and the person you are paired with will be Person A.

DECISION TASK 1: In the first input field you must make a decision in the role of Person A. You must choose between IN and OUT.

DECISION TASK 2: In the second input field you must make a decision in the role of Person B. We want to know what you as Person B would do if Person A chooses IN. You must choose between LEFT and RIGHT.

The screen also has a final input field for a PREDICTION TASK. Here you must enter a prediction about how many of the other participants in this room will choose RIGHT when they make a decision in the role of Person B.

Once you have completed the decision and prediction tasks you should click on the "Submit" button. You will then be prompted to either change or confirm your decisions and predictions. At this point, if you want to you will be able to go back and change your entries. Once you confirm your decisions and predictions you cannot change them. When everyone in the room has submitted and confirmed their decisions and predictions earnings will be calculated.

\section{How Your Earnings Are Determined}

First the computer will randomly determine your actual role in the decision situation. This will determine which of your choices (in Decision Task 1 or in Decision Task 2) is relevant for the computation of earnings:

- There is a 50\% chance that you are Person A and the person you are paired with is Person B. In this case, your choice in Decision Task 1 and the other person's choice in Decision Task 2 will be relevant.

- There is a 50\% chance that you are Person B and the person you are paired with is Person A. In this case, your choice in Decision Task 2 and the other person's choice in Decision Task 1 will be relevant.

The relevant decisions made by you and the person you are paired with will then be used to calculate earnings as shown in the Figure above.

In addition, you can earn points from the PREDICTION TASK. Your prediction in the PREDICTION TASK will be compared with the actual number of participants who chose RIGHT in the role of Person B. If your prediction is correct you will receive 10 additional points.

Your point earnings from the decision situation and the prediction task will then be summed and converted to cash at a rate of 15 pence per point. If Part 1 of the experiment is selected for payment, you will be paid this amount in private and cash at the end of the experiment.

We now want to check that each participant understands how their earnings from Part 1 will be calculated. To do this we ask you to answer some questions. In a couple of minutes the experimenter will check your answers. When each participant has answered all questions correctly we will continue with the experiment. 


\section{Questions}

1. How many periods will there be in Part 1 of the experiment?

2. How many other people are you matched with in Part 1 of the experiment?

3. Suppose that the person you are paired with chooses OUT as Person A and RIGHT as Person B. Suppose you choose IN as Person A and LEFT as Person B. If the computer randomly determines that you are Person A and the person you are paired with is Person B ....

What will be your earnings from the decision situation?

What will be the other person's earnings from the decision situation?

4. Suppose that the person you are paired with chooses OUT as Person A and LEFT as Person B. Suppose you choose IN as Person A and RIGHT as Person B. If the computer randomly determines that you are Person B and the person you are paired with is Person A ....

What will be your earnings from the decision situation?

What will be the other person's earnings from the decision situation?

\section{Beginning the Experiment}

If you have any questions please raise your hand and an experimenter will come to your desk to answer it.

We are now ready to begin Part 1 of the experiment. Please look at your computer screen and begin making your decisions.

\section{The Decision Screen}

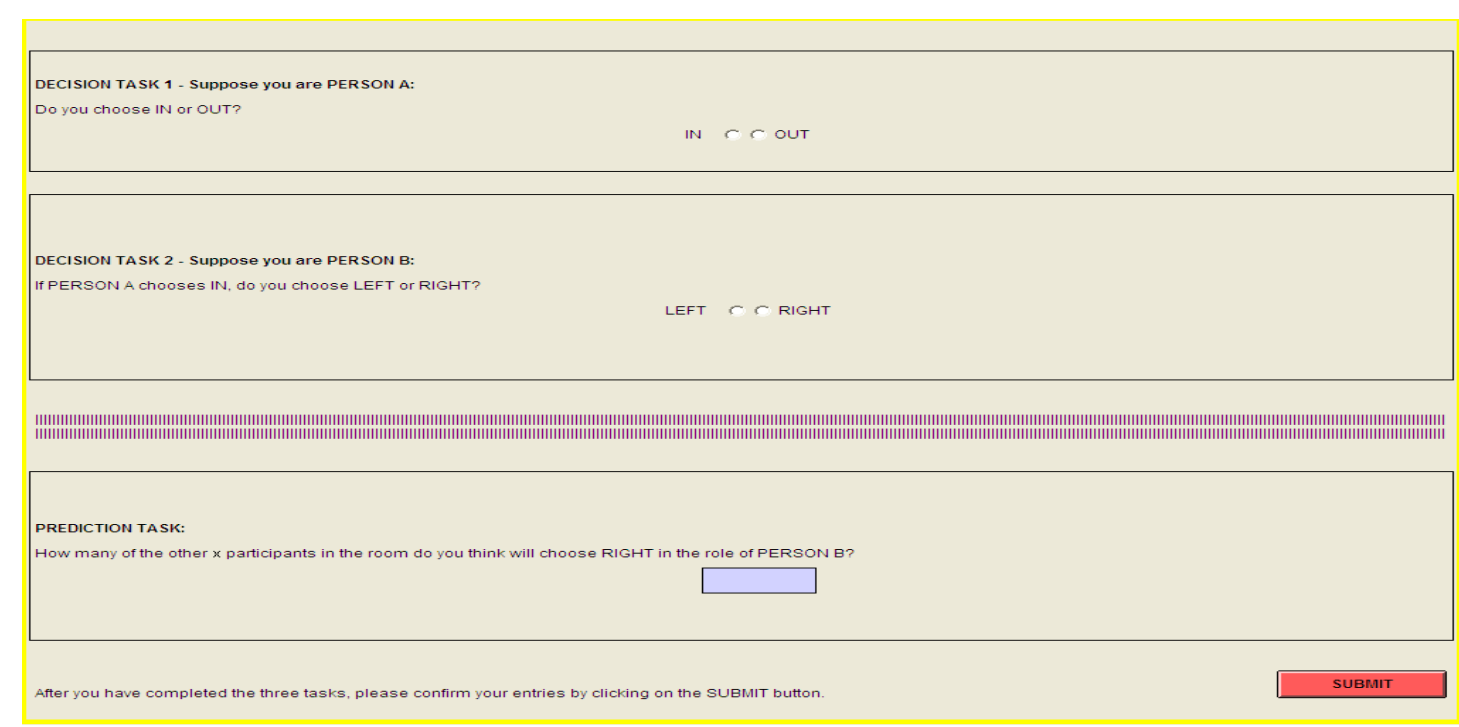




\section{Part 2 - Instructions (differences between treatments in brackets)}

\section{General}

In this part of the experiment you will be matched with one other person, randomly selected from the participants in this room, to form a group of two. At the end of Part 2 the group will be dissolved, and you will not be matched with this person again during this experiment.

Your earnings in Part 2 will depend on the decisions made within your group, as described below. Your earnings will not be affected by decisions made in other groups. All decisions are made anonymously and you will not learn the identity of the other participant in your group.

Your earnings in Part 2 will be calculated in points. At the end of Part 2 your point earnings will be converted into cash at the exchange rate of 15 pence per point. If Part 2 is selected for payment, you will be paid this amount in private and in cash at the end of the experiment.

\section{The Decision Situation}

Your earnings in Part 2 of the experiment will depend on the decisions made in the following decision situation. You will be in this decision situation only once (i.e. there is only one period in Part 2 of the experiment).

At the beginning of the decision situation you will be endowed with 20 tokens. Similarly, the other member of your group will be endowed with 20 tokens.

You can use these tokens to earn points in a Two-Person Task where you and the other group member have to make the following allocation decision. You must choose how many of your 20 tokens to allocate to a group account and how many to keep in your private account. At the same time that you are making your decision the other member of your group must choose how many of his or her 20 tokens to allocate to the group account and how many to keep in his or her private account.

You will make your allocation decision on a screen like the one shown below. You must enter the number of tokens you allocate to the group account. Any tokens you do not allocate to the group account will automatically be kept in your private account.

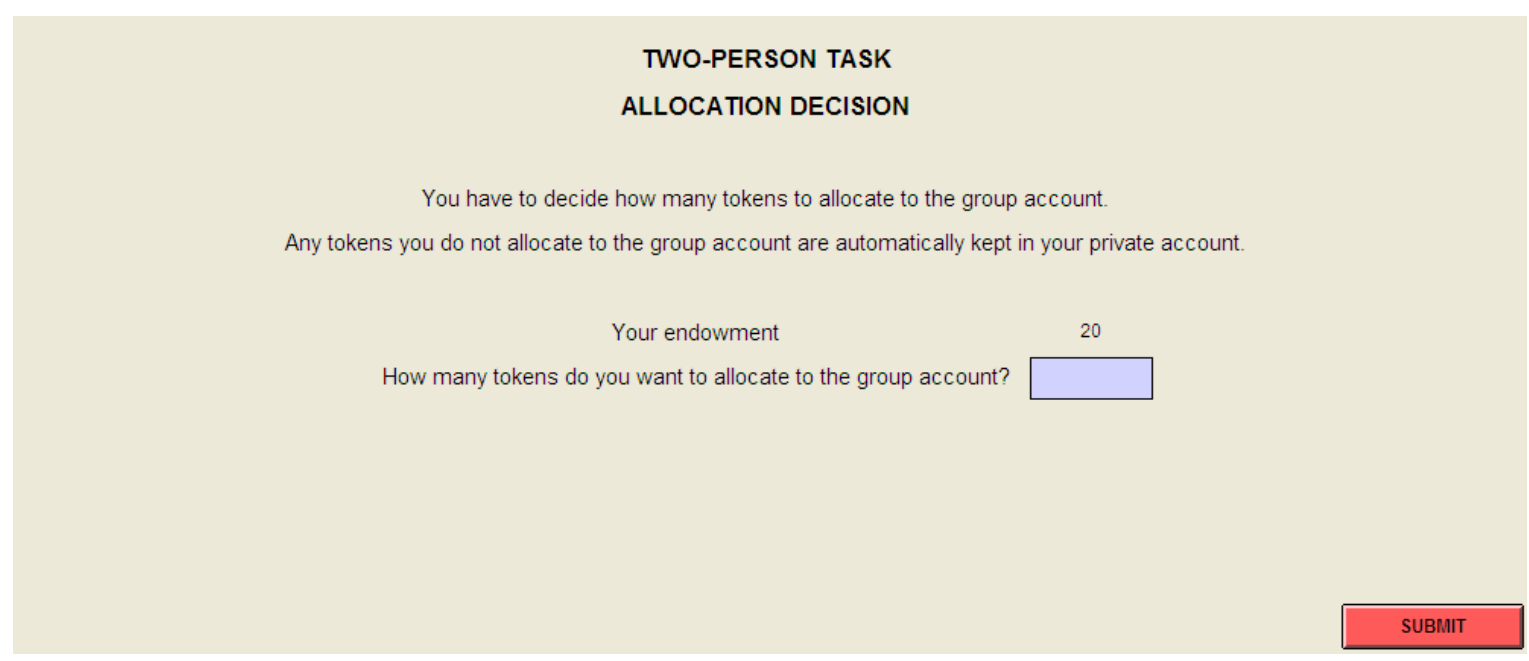


Your earnings will be determined as follows:

For each token you keep in your private account you will earn 3 points.

For each token you allocate to the group account you and the other member of your group will earn 2 points each.

Similarly, for each token the other group member keeps in his or her private account he or she will earn 3 points, and for each token he or she allocates to the group account both group members will earn 2 points each.

Your point earnings will be the sum of your earnings from your private account and the group account.

Thus:

\section{Your point earnings in the Two-Person Task $=3 \times$ (number of tokens kept in your private account $)+$ $2 \times$ (total number of tokens allocated to the group account by yourself and the other member of your group).}

After you and the other group member have made a decision, you will be informed of the allocation decisions and earnings in your group.

We now want to check that each participant understands how their earnings from the Two-Person Task will be calculated. To do this we ask you to answer some questions. You will find these on the next page. In a couple of minutes the experimenter will check your answers. When each participant has answered all questions correctly we will continue with the experiment.

\section{Questions}

1. How many periods will there be in Part 2 of the experiment?

2. How many people are in your group (including yourself)?

3. Suppose the other group member allocates 0 tokens to the group account. If you allocate 0 tokens to the group account ....

How many tokens do you keep in your private account?

What will be your earnings from your private account?

What is the total number of tokens allocated to the group account?

What will be your earnings from the group account?

What will be your total earnings?

4. Suppose the other group member allocates 20 tokens to the group account. If you allocate 20 tokens to the group account ....

How many tokens do you keep in your private account?

What will be your earnings from your private account?

What is the total number of tokens allocated to the group account?

What will be your earnings from the group account?

What will be your total earnings? 
5. Suppose the other group member allocates 2 tokens to the group account. If you allocate 18 tokens to the group account ....

How many tokens do you keep in your private account?

What will be your earnings from your private account?

What is the total number of tokens allocated to the group account?

What will be your earnings from the group account?

What will be your total earnings?

6. Suppose the other group member allocates 18 tokens to the group account. If you allocate 2 tokens to the group account ....

How many tokens do you keep in your private account?

What will be your earnings from your private account?

What is the total number of tokens allocated to the group account?

What will be your earnings from the group account?

What will be your total earnings?

\section{[BASELINE:}

\section{What happens next?}

In summary, the structure of Part 2 of the experiment is as follows:

Step 1 - You will be randomly matched with another person in this room to form a group of two. You and the other group member will be endowed with 20 tokens each.

Step 2 - You and the other group member will make an allocation decision in the Two-Person Task. You will choose how many of your tokens to allocate to a group account and how many to keep in your private account. You and the other group member will then be informed of the allocation decisions made in your group and the resulting earnings.

Step 3 - Your point earnings from Part 2 will be converted to cash at a rate of 15 pence per point. If Part 2 of the experiment is selected for payment, you will be paid this amount in private and cash.

\section{Beginning the experiment}

If you have any questions please raise your hand and an experimenter will come to your desk to answer it.

We are now ready to begin Part 2 of the experiment. Please look at your computer screen and begin making your decisions.]

\section{[ UNCONDITIONAL:}

Participation in the Two-Person Task is voluntary. If you do not wish to participate in the Two-Person Task you can opt for an Individual Task. In this case your 20 tokens will automatically be allocated to an individual account from which you earn 61 points in total. Similarly, the 20 tokens of the other group member will be allocated to his or her individual account from which he or she earns 61 points in total. 
You and the other group member will choose whether to be paid according to the Two-Person Task or the Individual Task before you make an allocation decision in the Two-Person Task.

If both you and the other group member choose the Two-Person Task, then you and the other group member will have to decide how to allocate your tokens between the group account and the private account, and your earnings will be calculated accordingly.

If either you or the other group member chooses the Individual Task, you will not make an allocation decision in the Two-Person Task. Your 20 tokens will automatically be allocated to your individual account and your earnings will be 61 points.

\section{What happens next?}

In summary, the structure of Part 2 of the experiment is as follows:

Step 1 - You will be randomly matched with another person in this room to form a group of two. You and the other group member will be endowed with 20 tokens each.

Step 2 - You and the other group member will independently and privately choose whether to be paid according to the Two-Person Task or the Individual Task.

Step 3 - If both you and the other group member choose the Two-Person Task, you and the other group member will make an allocation decision. You will choose how many of your tokens to allocate to a group account and how many to keep in your private account. You and the other group member will then be informed of the allocation decisions made in your group and the resulting earnings in Part 2 of the experiment.

If either you or the other group member chooses the Individual Task, you will not make an allocation decision in Step 3. You and the other group member will earn 61 points each in Part 2 of the experiment.

Step 4 - Your point earnings from Part 2 will be converted to cash at a rate of 15 pence per point. If Part 2 of the experiment is selected for payment, you will be paid this amount in private and cash.

\section{Beginning the experiment}

If you have any questions please raise your hand and an experimenter will come to your desk to answer it.

We are now ready to begin Part 2 of the experiment. Please look at your computer screen and begin making your decisions.]

\section{[CONDITIONAL:}

Participation in the Two-Person Task is voluntary. If you do not wish to participate in the Two-Person Task you can opt for an Individual Task. In this case your 20 tokens will automatically be allocated to an individual account from which you earn 61 points in total. Similarly, the 20 tokens of the other group member will be allocated to his or her individual account from which he or she earns 61 points in total.

You and the other group member will choose whether to be paid according to the Two-Person Task or the Individual Task after you have made an allocation decision in the Two-Person Task and you have been informed of the decisions in your group and the corresponding earnings.

If both you and the other group member choose the Two-Person Task, then your allocation decisions will be implemented and your earnings confirmed. 
If either you or the other group member chooses the Individual Task, then your allocation decisions will not be implemented. Your 20 tokens will automatically be allocated to your individual account and your earnings will be 61 points.

\section{What happens next?}

In summary, the structure of Part 2 of the experiment is as follows:

Step 1 - You will be randomly matched with another person in this room to form a group of two. You and the other group member will be endowed with 20 tokens each.

Step 2 - You and the other group member will make an allocation decision in the Two-Person Task. You will choose how many of your tokens to allocate to a group account and how many to keep in your private account. You and the other group member will then be informed of the allocation decisions made in your group and the resulting earnings.

Step 3 - You and the other group member will independently and privately choose whether to be paid according to the Two-Person Task or the Individual Task.

If both you and the other group member choose the Two-Person Task your allocation decisions in Step 2 will be implemented, and your earnings in Part 2 of the experiment will be as shown in Step 2.

If either you or the other group member chooses the Individual Task, your allocation decisions in Step 2 will not be implemented. You and the other group member will earn 61 points each in Part 2 of the experiment.

Step 4 - Your point earnings from Part 2 will be converted to cash at a rate of 15 pence per point. If Part 2 of the experiment is selected for payment, you will be paid this amount in private and cash.]

\section{Beginning the experiment}

If you have any questions please raise your hand and an experimenter will come to your desk to answer it.

We are now ready to begin Part 2 of the experiment. Please look at your computer screen and begin making your decisions.] 